\title{
Hemostatic effects of fibrinogen concentrate compared with cryoprecipitate in children after cardiac surgery: A randomized pilot trial
}

Filomena R. B. G. Galas, MD, PhD, Juliano P. de Almeida, MD, PhD, Júlia T. Fukushima, MSc, Jean Louis Vincent, MD, PhD, Eduardo A. Osawa, MD, PhD, Suely Zeferino, RN, Lígia Câmara, RN, Vanessa A. Guimarães, MD, Marcelo B. Jatene, MD, PhD, and Ludhmila A. Hajjar, MD, PhD

Objectives: Acute acquired hypofibrinogenemia in children undergoing cardiac surgery is a major concern because it often results in perioperative bleeding and high rates of allogeneic blood transfusion. Fibrinogen concentrate has been proposed as an alternative to cryoprecipitate (the gold standard therapy), with minimal infectious and immunologic risks. Our objective was to investigate the efficacy and safety of fibrinogen concentrate in children undergoing cardiac surgery.

Methods: In this randomized pilot study, patients were allocated to receive fibrinogen concentrate $(60 \mathrm{mg} / \mathrm{kg})$ or cryoprecipitate $(10 \mathrm{~mL} / \mathrm{kg})$ if bleeding was associated with fibrinogen levels $<1 \mathrm{~g} / \mathrm{dL}$ after cardiopulmonary bypass weaning. The primary outcome was postoperative blood losses during the 48 hours after surgery.

Results: A total of 63 patients were included in the study, 30 in the fibrinogen concentrate group and 33 in the cryoprecipitate group. The median 48-hour blood loss was not significantly different between the 2 groups (320 mL [interquartile range, $157-750$ ] vs $410 \mathrm{~mL}$ [interquartile range, 215-510], respectively; $P=.672$ ). After treatment, plasma fibrinogen concentration increased similarly following administration of both products. There were no differences in allogeneic blood transfusion after intervention treatment.

Conclusions: A large trial comparing fibrinogen concentrate and cryoprecipitate in the management of children with acute acquired hypofibrinogenemia during heart surgery is feasible. The preliminary results of our study showed that the use of fibrinogen concentrate was as efficient and safe as cryoprecipitate in the management of bleeding children undergoing cardiac surgery. (J Thorac Cardiovasc Surg 2014;148:1647-55)

Bleeding is a significant cause of mortality after cardiac surgery. It is associated with high rates of allogeneic blood transfusion, which in turn results in worse outcomes. ${ }^{1}$ In cardiac surgery, reduced fibrinogen levels increase bleeding due to compromise in fibrin production and platelet aggregation. $^{2-4}$ Fibrinogen can be supplemented by the administration of fresh frozen plasma (FFP), cryoprecipitate, or fibrinogen concentrate. FFP and cryoprecipitate are both allogeneic blood products that require cross-matching and thawing before administration and are also related to increased risk of pathogen transmission and immunologic reactions. ${ }^{2,5}$ Alternatively, fibrinogen concentrate is a plasma-derived submitted to pasteurization that minimizes the risk of immunologic and allergic reactions. ${ }^{5,6}$

\footnotetext{
From the Surgical Intensive Care Unit, InCor Heart Institute, University of Sao Paulo, Sao Paulo, Brazil.

Disclosures: The trial was supported by CSL Behring Ltd. (Sao Paulo, Brazil), which provided the study drug and the testing of clotting factors and thromboelastometry. Authors have nothing to disclose with regard to commercial support.

Received for publication Dec 18, 2013; revisions received April 7, 2014; accepted for publication April 11, 2014; available ahead of print June 18, 2014.

Address for reprints: Ludhmila Abrahão Hajjar, $\mathrm{MD}, \mathrm{PhD}$, Heart Institute, Av Dr Eneas Carvalho Aguiar, 44, Sao Paulo, Brazil 05403000 (E-mail: ludhmila@usp.br).

$0022-5223 / \$ 36.00$

Copyright $(2014$ by The American Association for Thoracic Surgery

http://dx.doi.org/10.1016/j.jtcvs.2014.04.029
}

Previous studies have demonstrated that fibrinogen concentrate effectively increases plasma fibrinogen levels and controls perioperative bleeding in adult patients undergoing cardiopulmonary bypass (CPB) surgery. ${ }^{3,7}$ However, the clinical efficacy of fibrinogen concentrate for management of perioperative bleeding has not been compared directly with cryoprecipitate.

We hypothesized that fibrinogen concentrate would be similar to cryoprecipitate in reducing bleeding in children undergoing cardiac surgery without increasing the rate of adverse effects.

\section{METHODS \\ Study Design}

This study was designed as a pilot trial. It was a prospective, randomized controlled trial conducted during 2 consecutive years at the Heart Institute of the University of Sao Paulo, Brazil. The study was approved by the Heart Institute Ethics Committee, Clinics Hospital, University of Sao Paulo, and written informed consent was obtained from parents or legal guardians. The authors designed the trial protocol, collected the data, directed the statistical plan, and wrote the manuscript. CSL Behring provided the study medication and supported the laboratory analysis.

\section{Participants}

Patients younger than age 7 years scheduled for elective cardiac surgery with CPB were preoperatively screened for eligibility. Exclusion criteria 


$$
\begin{aligned}
& \text { Abbreviations and Acronyms } \\
& \begin{aligned}
\text { CPB } & =\text { cardiopulmonary bypass } \\
\text { FFP } & =\text { fresh frozen plasma } \\
\text { FIBTEM }= & \text { fibrin-based thromboelastometric } \\
& \text { clotting assay } \\
\text { ICU }= & \text { intensive care unit } \\
\text { RBC } & \text { red blood cell } \\
\text { ROTEM } & =\text { rotational thromboelastometry }
\end{aligned}
\end{aligned}
$$

were inability to receive blood products, enrolment in another study, chronic anemia (preoperative hemoglobin $<10 \mathrm{~g} / \mathrm{dL}$ ), a history of coagulopathy or preoperative coagulopathy (platelet count $<100,000 \mathrm{~mL} / \mathrm{mm}^{3}$ or prothrombin time $>14.8$ seconds), active infection, or hypersensitivity to fibrinogen concentrate.

Eligible patients were included in the study after heparin neutralization if 2 inclusion criteria were fulfilled: diffuse bleeding from capillary beds at wound surfaces requiring haemostatic therapy and plasma fibrinogen concentration $<1 \mathrm{~g} / \mathrm{L}$.

Patients were randomly assigned in a $1: 1$ ratio to receive $60 \mathrm{mg} / \mathrm{kg}$ pasteurized human fibrinogen concentrate (Haemocomplettan P, CSL Behring, Marburg, Germany) or $10 \mathrm{~mL} / \mathrm{kg}$ cryoprecipitate. In our hospital, the cryoprecipitate is available in single bags, in a total mean volume of $25 \mathrm{~mL}$ per bag. Each unit of cryoprecipitate has approximately $150 \mathrm{mg}$ fibrinogen.

Opaque envelopes arranged using a random-number table were prepared by the chief statistician and opened sequentially to determine the patient's treatment group. The research coordinator enrolled the participants and obtained informed consent. Outcome assessors and patients were unaware of study group assignments.

\section{Anesthesia, CPB, and Surgery Methods}

For all patients, anesthesia, CPB, and surgery were performed by the same team of cardiac surgeons, perfusionists, and anesthetists. Anesthesia was induced with fentanyl (3-5 $\mu \mathrm{g} / \mathrm{kg})$, ketamine $(1 \mathrm{mg} / \mathrm{kg})$, and pancuronium bromide $(0.1 \mathrm{mg} / \mathrm{kg})$. Maintenance was performed with sevoflurane in oxygen and fentanyl as needed. All patients were monitored using arterial and central venous catheters.

Dobutamine or milrinone were used as inotropic drugs, and norepinephrine or epinephrine as vasopressors. Methylprednisolone $(10 \mathrm{mg} / \mathrm{kg})$ and cefuroxime $(50 \mathrm{mg} / \mathrm{kg})$ were administered intravenously at the introduction of anesthesia. All patients received antifibrinolytic prophylaxis with $\varepsilon$-aminocaproic acid $(100 \mathrm{mg} / \mathrm{kg}$ ) as a loading dose given before anesthetic induction, followed by a $50 \mathrm{mg} / \mathrm{kg} / \mathrm{h}$ infusion, which continued until the end of surgery.

Anticoagulation therapy was established with an initial dose of $4 \mathrm{mg} / \mathrm{kg}$ heparin in the central venous line before bypass initiation, with a target activated clotting time of 480 seconds, using kaolin as the activating agent (ACT II HemoTec; Medtronic, Rueil Malmaison, France). Additional heparin was administered intermittently to titrate clotting times during bypass. A centrifugal pump (Medtronic Biomedicus; Medtronic, Minneapolis, Minn) was used for bypass. An extracorporeal circuit containing a microporous polypropylene membrane oxygenator (Braile; Sao Jose do Rio Preto, São Paulo, Brazil) with an integrated venous cardiotomy reservoir was used. The oxygenator was primed with lactated Ringer's solution containing $0.5 \mathrm{~g} / \mathrm{kg}$ mannitol and $2500 \mathrm{U}$ heparin. Packed red blood cells (RBCs) were added to the solution to maintain the $\mathrm{CPB}$ hematocrit value at $25 \%$, and $8.4 \%$ sodium bicarbonate was added to correct the $\mathrm{pH}$ to 7.35 to 7.40 . A hypothermic temperature management strategy $\left(28^{\circ} \mathrm{C}-32^{\circ} \mathrm{C}\right)$ with $\alpha$-stat blood gas management was used in all patients during bypass. After aortic crossclamping the heart was arrested by anterograde infusion of a cold blood cardioplegic solution. Fluid management was performed with lactated Ringer's solution and adjusted according to filling pressures, urine output, and central venous saturation.

Following surgery, patients were rewarmed to $36^{\circ} \mathrm{C}$ and weaned from CPB. To reverse the anticoagulant effect of heparin, protamine chloride was administered intravenously (30 U/kg). Additional protamine was administered as required to return activated clotting times to preoperative values. Patients were transferred to the intensive care unit (ICU) before recovery from anesthesia.

\section{Coagulation Tests}

Laboratory coagulation tests, including platelet count, hemoglobin and hematocrit, fibrinogen concentration, prothrombin time, international normalized ratio, and activated partial thromboplastin time, were performed using the fully automated analyzers STA-R Evolution (Roche AG, Grenzach-Wyhlen, Germany) and Sysmex XE 2001 (Sysmex $\mathrm{GmbH}$, Norderstedt, Germany). These results were immediately available to be applied to the care of bleeding patients during the study.

Clotting activities of factor II, VII, IX, X, and XIII were determined by a 1-stage method on a Thrombolyzer ChromEquipment (Benk Electronic, Norderstedt, Germany), using plasmas deficient in factor II, VII, X, and $\mathrm{X}$ (Cryocheck, Dartmouth, Canada) as substrate, and recombinant human tissue factor (Innovin; Dade Behring GmbH, Marburg, Germany) or Platelin LS (Biomerieux, Herlev, Denmark) as the activating agent. Factor XIII transglutaminase activity was determined using the Berichrom FXIII kit, on an automated coagulation analyzer (Dade Behring Coagulation Timer; Dade Behring $\mathrm{GmbH}$ ). Coagulation tests were performed in both groups at fixed time points: before randomization (T0) and 1 hour after study drug infusion (T1). These results were not available to the patients. They were evaluated post-hoc. Fibrinogen levels were dosed in both groups at fixed timed points: T0; T1; and 2 hours, 24 hours, and 48 hours (T4) after study drug infusion.

Thromboelastometry was performed using the rotational thromboelastometry (ROTEM) device (Tem International GmbH, Munich, Germany). ROTEM plastic cups prewarmed to $37^{\circ} \mathrm{C}$ were loaded with $300 \mu \mathrm{L}$ whole blood and $20 \mu \mathrm{L}$ investigational hemostatic agent. The coagulation process was activated with tissue factor (Innovin; Dade Behring $\mathrm{GmbH}$ ). Standard ROTEM reagents were used for intrinsic, extrinsic, and fibrin-based (FIBTEM) thromboelastometric clotting assays. Clotting time, clot formation time, and maximum clot firmness parameters were recorded. The tests were performed in both groups at fixed time points: T0, T1, 24 hours, and $\mathrm{T} 4$.

\section{Treatment Groups}

After randomization, bleeding patients with fibrinogen levels $<1 \mathrm{~g} / \mathrm{L}$ were allocated to 1 of 2 treatments: fibrinogen concentrate (Haemocomplettan P, CSL Behring $\mathrm{GmbH}$ ) in a intravenous dose of $60 \mathrm{mg} / \mathrm{kg}$ or cryoprecipitate in a dose of $10 \mathrm{~mL} / \mathrm{kg}$ (Figure 1). The trigger of fibrinogen levels $<1 \mathrm{~g} / \mathrm{L}$ was chosen based on previous studies showing an association between these values and bleeding after cardiac surgery.

During pump weaning in the operating room, in all cases, both fibrinogen concentrate and cryoprecipitate were both already prepared and available to be administered. After randomization, fibrinogen concentrate or cryoprecipitate was administered immediately after bleeding identification and the other 1 was dropped out. Both fibrinogen concentrate and cryoprecipitate were used as a first-line therapy for hemostasis, and no other products were given before this first intervention.

\section{Data Collection}

Demographic and clinical data for the calculation of the risk-adjusted classification for congenital heart surgery were obtained for each patient at the time of randomization. ${ }^{10}$ Data regarding the type of surgical procedure, bypass duration, number and type of allogeneic units transfused (including RBC, platelets, FFP, and additional cryoprecipitate) were 


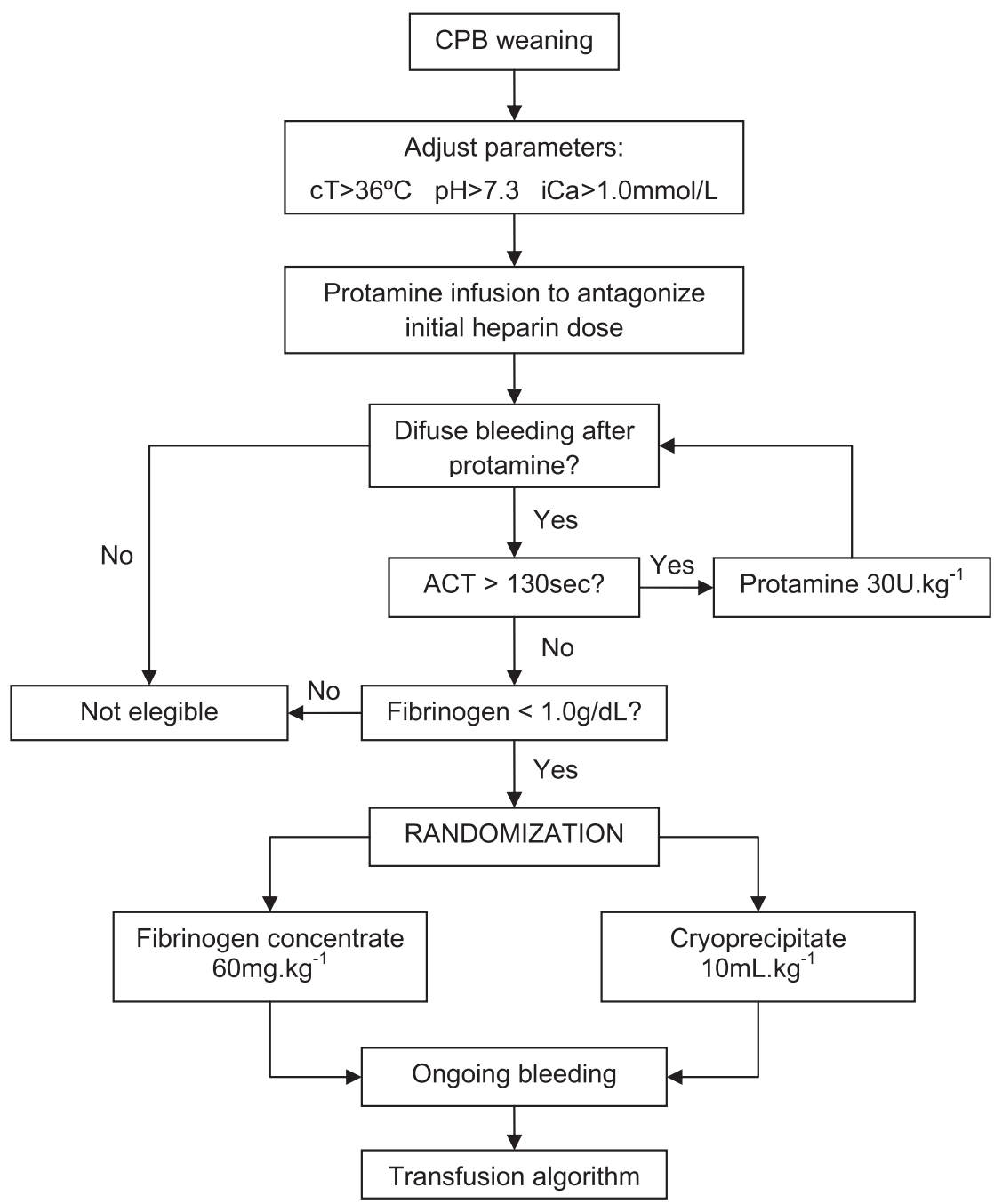

FIGURE 1. Protocol of treatment. $C P B$, Cardiopulmonary bypass; $c T$, central temperature; $i C a$, ionized calcium; $A C T$, Activated Clotting Time.

recorded. Also recorded were the amount and type of fluids administered. During ICU stay, clinical data were collected daily by 2 blinded assessors (trained physicians with more than 3 years' experience in the cardiac ICU). Data regarding hemodynamic status were also recorded, including need for vasoactive drugs and other medications, need for mechanical ventilation, need for dialysis, and other organ dysfunction. During the hospital stay, data regarding the use of RBC transfusion; hematocrit goals; severe clinical complications (including readmission to the ICU, surgical reintervention); and death were collected.

After weaning from $\mathrm{CPB}$, neutralization of heparin, and completion of surgical hemostasis, all blood was removed from the surgical field by suction, and surgical swabs were then inserted for 5 minutes to absorb any additional blood that arose from active bleeding. A 5-minute bleeding mass was determined by weighing dry surgical cloths and compresses, applying them to surgical area for 5 minutes, and weighing them again.

\section{Study Outcomes}

The primary outcome was postoperative blood losses during 48 hours after surgery.

Secondary outcomes were the percentage of patients exposed to allogeneic blood products (RBCs, FFP, platelet concentrate, and cryoprecipitate), duration of mechanical ventilation, vasopressor requirement, and incidence of acute myocardial infarction, stroke, acute kidney injury requiring dialysis, septic shock, reoperation, peripheral artery occlusion, deep venous thrombosis, and pulmonary embolism, and death up to postoperative day 7 or hospital discharge.

Secondary outcomes also included ICU and hospital length of stay, coagulation parameters, ROTEM values, and fibrinogen dose before and after intervention.

\section{Transfusion Protocol}

Perioperative transfusion practice was standardized. RBC transfusion was mandatory for hemoglobin $<6.0 \mathrm{~g} / \mathrm{dL}$, optional for hemoglobin between 6.0 and $8.0 \mathrm{~g} / \mathrm{dL}$, acceptable for hemoglobin between 8.0 and $10.0 \mathrm{~g} / \mathrm{dL}$, and not permitted for higher hemoglobin values. Transfusions were to be administered $1 \mathrm{U}$ at a time. Coagulation products were only to be administered if, after protocol treatment, patients persisted bleeding $2 \mathrm{~mL} / \mathrm{kg}$ or more over 30 minutes or $1.5 \mathrm{~mL} / \mathrm{kg}$ or more per hour over 2 consecutive hours. FFP (10-15 mL/ $\mathrm{kg}$ ) was to be administered if the international normalized ratio was 1.5 or higher. Platelets $(1 \mathrm{U} / 10 \mathrm{~kg})$ were to be transfused if the platelet count was $100,000 / \mathrm{mm}^{3}$ or lower. Cryoprecipitate $(1 \mathrm{U} / 10 \mathrm{~kg})$ was to be transfused if the fibrinogen concentration was $1.0 \mathrm{~g} / \mathrm{L}$ or lower. An external adjudication committee was established to ensure compliance with the transfusion protocol. 


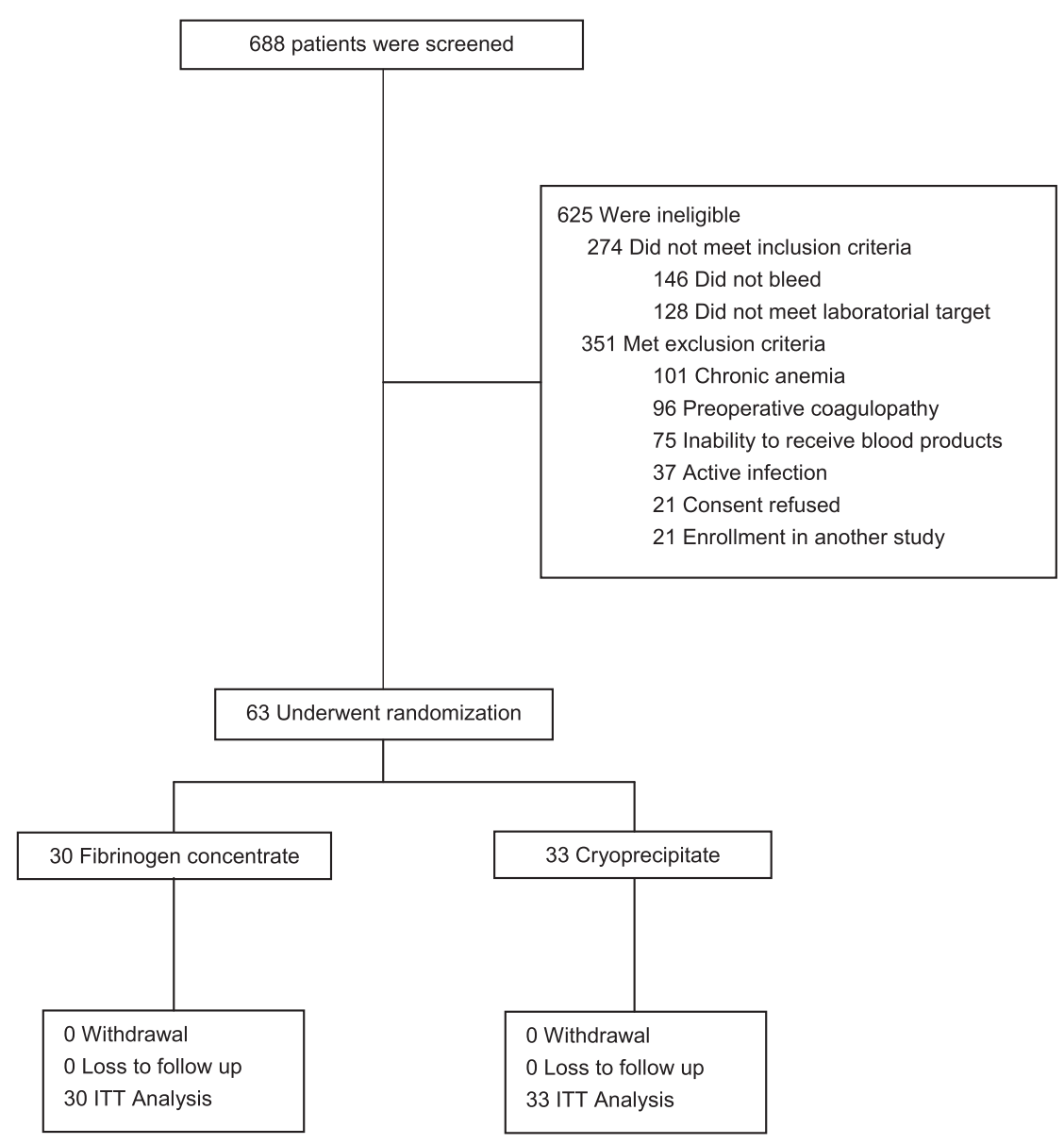

FIGURE 2. Flowchart of the study. ITT, Intention-to-treat.

\section{Safety}

An independent safety data monitoring committee was established to ensure the safety of patients. All adverse events, including severity, relation to trial product, and patient outcome, were reported from the time of trial drug administration until postoperative day 7 or hospital discharge. Prespecified critical adverse events were thromboembolic events (including acute myocardial infarction, stroke, transient ischemic attack, peripheral artery occlusion, deep venous thrombosis, and pulmonary embolism), renal dysfunction reoperation, and death.

\section{Statistical Analysis}

We compared baseline characteristics, follow-up measures, and clinical outcomes on an intention-to-treat basis according to the randomized study group assignment. Continuous variables were compared using the Student $t$ test for normally distributed variables; the Mann-Whitney $U$ test or Wilcoxon matched-pairs signed-rank test for non-normally distributed variables; and categorical variables were compared using the Pearson $\chi^{2}$ test, Fisher exact test, or likelihood ratio test. An intention-to-treat analysis was performed. We estimated that 60 patients would provide $80 \%$ power to detect a blood loss difference during the intervention period as small as $100 \mathrm{~mL}$ between the 2 groups.

Statistical analyses were performed using SPSS version 18.0 (IBM-SPSS Inc, Armonk, NY).

\section{RESULTS}

A total of 688 patients were assessed for eligibility and 63 fulfilled the inclusion criteria (Figure 2).
Thirty patients were randomized to the fibrinogen group and 33 to the cryoprecipitate group. No patients in either group were lost to follow-up or withdrew from the study. There were no between-group differences in baseline demographics and intraoperative characteristics (Table 1).

\section{Blood Loss}

Pretreatment blood mass was similar in the fibrinogen concentrate and cryoprecipitate groups $(111 \mathrm{~g}$; $95 \%$ confidence interval [CI], 104-118 g vs $122 \mathrm{~g}$; 95\% CI, 112-133 g, respectively). The median 48 -hour blood loss (intraoperative and 48-hour drainage) was not significantly different between the 2 groups ( $320 \mathrm{~mL}$ [IQR, 157-750 mL] vs 410 $\mathrm{mL}$ [IQR, 215-510 mL], respectively; $P=.672$ ).

\section{Blood Product Transfusion Requirement}

Table 2 shows the percentage of patients that were transfused with blood products in each group following therapeutic intervention with fibrinogen concentrate or cryoprecipitate up to 7 postoperative days. Patients in the fibrinogen group and cryoprecipitate group received, after treatment, similar amounts of allogeneic blood transfusion (RBC, $83.3 \%$ vs $97 \%$; $P=.094$; platelets, $0 \%$ vs $9.1 \%$; 
TABLE 1. Baseline and intraoperative characteristics of study patients

\begin{tabular}{|c|c|c|c|c|}
\hline Variable & $\begin{array}{c}\text { Total patients } \\
(\mathrm{N}=63) \\
\end{array}$ & $\begin{array}{c}\text { Fibrinogen } \\
\text { concentrate }(\mathbf{n}=\mathbf{3 0})\end{array}$ & $\begin{array}{c}\text { Cryoprecipitate } \\
(\mathbf{n}=\mathbf{3 3})\end{array}$ & $P$ value \\
\hline Age, mo & $3.5(1-51.6)$ & $4.7(1.2-57.3)$ & $3.2(0.9-48.1)$ & .698 \\
\hline Female & $28(44.4 \%)$ & $17(56.7 \%)$ & $11(33.3 \%)$ & .063 \\
\hline Weight, kg & $6.7(3.8-18.9)$ & $8.4(3.8-20.1)$ & $6(3.7-17.2)$ & .414 \\
\hline Height, cm & $65(54.5-110)$ & $65.5(57-117)$ & $64(52-104)$ & .790 \\
\hline Body mass index & $14.5(12.8-16.6)$ & $14.4(13-16.2)$ & $14.5(12.6-17.6)$ & .951 \\
\hline RACHS-1 & $3(2-4)$ & $3(2-3)$ & $3(2-4)$ & .102 \\
\hline Congenital heart disease & & & & .272 \\
\hline Left-right shunt & $15(23.8)$ & $8(26.7)$ & $7(21.2)$ & \\
\hline Single-ventricle & $12(19.0)$ & $7(23.3)$ & $5(15.2)$ & \\
\hline Left ventricle outflow tract obstruction & $7(11.1)$ & $1(3.3)$ & $6(18.2)$ & \\
\hline Conotruncal cardiac anomalies* & $21(33.3)$ & $9(30.0)$ & $12(36.4)$ & \\
\hline Other cardiac anomalies & $8(12.7)$ & $5(16.7)$ & $3(9.1)$ & \\
\hline Cardiac procedure & & & & .278 \\
\hline Correction of septal defects & $16(25.4)$ & $9(30.0)$ & $7(21.2)$ & \\
\hline Correction of single ventricles (first, second, and third stages) & $11(17.5)$ & $6(20.0)$ & $5(15.2)$ & \\
\hline Correction of left ventricle outflow tract obstruction & $7(11.1)$ & $1(3.3)$ & $6(18.2)$ & \\
\hline Correction of conotruncal cardiac anomalies & $21(33.3)$ & $9(30.0)$ & $12(36.4)$ & \\
\hline Other cardiac procedures & $8(12.7)$ & $5(16.7)$ & $3(9.1)$ & \\
\hline Redo operations & $7(11.1)$ & $4(13.3)$ & $3(9.1)$ & .700 \\
\hline CBP time, $\min$ & $121(95-160)$ & $117(102-132)$ & $136(120-151)$ & .098 \\
\hline Lowest temperature on $\mathrm{CBP},{ }^{\circ} \mathrm{C}$ & $28(25.1-29)$ & $28(27-30.1)$ & $27(23.1-28)$ & .080 \\
\hline Fluid balance, $\mathrm{mL}$ & $189(27-542)$ & $110(25-556.5)$ & $215(42.5-664)$ & .302 \\
\hline \multicolumn{5}{|l|}{ Hemoglobin, g/dL } \\
\hline D0 & $12(11.5-12.6)$ & $12.5(11.7-13.3)$ & $11.6(10.8-12.4)$ & .108 \\
\hline D1 & $10.9(10.2-11.5)$ & $11.2(10.2-12.1)$ & $10.6(9.7-11.4)$ & .351 \\
\hline D2 & $10.1(9.6-10.5)$ & $10.7(10.1-11.2)$ & $9.5(8.8-10.2)$ & $.015 \dagger$ \\
\hline D3 & $9.7(9.3-10.1)$ & $10.2(9.6-10.7)$ & $9.3(8.6-9.9)$ & .044 \\
\hline
\end{tabular}

Values for age, weight, height, RACHS-1, lowest temperature on CPB, and fluid balance are presented as median (interquartile range) based on Mann-Whitney $U$ test; value for gender is presented as $\mathrm{n}(\%)$ based on likelihood ratio test; values for body mass index and CPB time are presented as mean (95\% confidence interval) based on Student $t$ test; and values for congenital heart disease and cardiac procedure are presented as $\mathrm{n}(\%)$ based on $\chi^{2}$ test. $C B P$, Cardiopulmonary bypass; RACHS-1, risk-adjusted classification for congenital heart surgery (scoring scale from 1 [low mortality risk] to 6 [high mortality risk]). *Conotruncal anomalies refer to a group of congenital heart defects involving the outflow tracts of the heart and the great vessels. †Statistically significant at $P<.05$

$P=.240 ;$ FFP, $10 \%$ vs $24.2 \% ; P=.137$; and cryoprecipitate, $43.3 \%$ vs $42.4 \% ; P=.942)$.

\section{Coagulation Tests}

The results of the coagulation analyses are presented in Table 3. At T0 there was no difference between groups in the levels of factors II, VII, IX, X, and XIII. Compared with baseline values, at $\mathrm{T} 1$, patients from the fibrinogen group exhibited higher levels of factors VII and IX, whereas patients from the cryoprecipitate group exhibited higher levels of factors II, VII, IX, and X. At T1, patients in the cryoprecipitate group had higher levels of factors II, VII, and X compared with patients in the fibrinogen group.

ROTEM results showed significant differences between groups before randomization, and at all time points up to T4 (Table 4). Treatment with both fibrinogen concentrate and cryoprecipitate increased FIBTEM maximum clot firmness at T1 and levels were maintained until T4.

\section{Fibrinogen Levels}

Plasma fibrinogen concentrations increased after the administration of study medication; these concentrations

TABLE 2. Transfusion of allogeneic blood products following study drug administration

\begin{tabular}{|c|c|c|c|c|}
\hline Variable & Total $(N=63)$ & Fibrinogen concentrate $(n=30)$ & Cryoprecipitate $(\mathbf{n}=\mathbf{3 3})$ & $P$ value \\
\hline Postoperative transfusion & $59(93.7)$ & $26(86.7)$ & $33(100.0)$ & $.046^{*}$ \\
\hline Red blood cells & $57(90.5)$ & $25(83.3)$ & $32(97)$ & .094 \\
\hline Platelets & $3(4.8)$ & $0(0)$ & $3(9.1)$ & .240 \\
\hline Fresh frozen plasma & $11(17.5)$ & $3(10)$ & $8(24.2)$ & .137 \\
\hline Cryoprecipitate & $27(42.9)$ & $13(43.3)$ & $14(42.4)$ & .942 \\
\hline
\end{tabular}

Values for platelets, fresh frozen plasma, and cryoprecipitate are presented as $\mathrm{n}(\%)$ based on $\chi^{2}$ test; values for postoperative transfusion and red blood cells are presented as $\mathrm{n}(\%)$ based on Fisher exact test. Boldface indicates total transfusions. *Statistically significant at $P<.05$. 
TABLE 3. Levels of coagulation factors before and after study treatment

\begin{tabular}{|c|c|c|c|c|}
\hline Factor & Time & Fibrinogen concentrate (A) & Cryoprecipitate (B) & $\mathbf{A} \times \mathbf{B}$ \\
\hline \multirow[t]{3}{*}{ Factor II, \% } & T0 & $42.1(37.3-46.9)$ & $39.6(34.5-44.6)$ & .267 \\
\hline & $\mathrm{T} 1$ & $44.0(37.7-50.3)$ & $49.4(43.2-55.7)$ & .020 \\
\hline & $\mathrm{T} 0 \times \mathrm{T} 1 \dagger$ & 0.405 & $<0.001$ & \\
\hline \multirow[t]{3}{*}{ Factor VII, \% } & T0 & $39.2(33.9-44.5)$ & $37.3(32.0-42.5)$ & .533 \\
\hline & $\mathrm{T} 1$ & $48.1(39.8-56.3)$ & $55.8(48.1-63.4)$ & .017 \\
\hline & $\mathrm{T} 0 \times \mathrm{T} 1 \dagger$ & 0.006 & $<0.001$ & \\
\hline \multirow[t]{3}{*}{ Factor IX, \% } & T0 & $74.6(66.3-82.9)$ & $72.7(60.8-84.6)$ & .693 \\
\hline & $\mathrm{T} 1$ & $78.4(69.5-87.4)$ & $85.1(75.6-94.7)$ & .693 \\
\hline & $\mathrm{T} 0 \times \mathrm{T} 1 \dagger$ & 0.020 & 0.020 & \\
\hline \multirow[t]{3}{*}{ Factor X, \% } & T0 & $43.8(37.8-49.7)$ & $41.9(37.7-46.0)$ & .660 \\
\hline & $\mathrm{T} 1$ & $44.7(37.7-51.7)$ & $49.4(43.8-55.1)$ & .001 \\
\hline & $\mathrm{T} 0 \times \mathrm{T} 1 \dagger$ & 0.401 & 0.036 & \\
\hline \multirow[t]{3}{*}{ Factor XIII, \% } & T0 & $80.6(71.5-89.6)$ & $77.4(57.7-97.1)$ & .825 \\
\hline & $\mathrm{T} 1$ & $80.2(72.4-88.1)$ & $87.3(71.7-102.8)$ & .825 \\
\hline & $\mathrm{T} 0 \times \mathrm{T} 1 \dagger$ & 0.076 & 0.076 & \\
\hline
\end{tabular}

Values are presented as median (interquartile range) or result. $T 0$, Before randomization; $T 1,1$ hour after infusion of study drug. $*$ Based on Mann-Whitney $U$ test. $\dagger$ Based on Wilcoxon matched-pairs signed-rank test.

were similar in the 2 groups at all time points up to $\mathrm{T} 4$ (Figure 3).

\section{Clinical Outcomes and Adverse Events}

Secondary outcomes were the percentage of patients exposed to allogeneic blood products (RBCs, FFP, platelet concentrate, and cryoprecipitate); duration of mechanical ventilation; vasopressor requirement; and incidence of acute myocardial infarction, stroke, acute kidney injury requiring dialysis, septic shock, reoperation, peripheral artery occlusion, deep venous thrombosis, and pulmonary embolism, as well as death up to postoperative day 7 or hospital discharge.

There were no significant differences between the fibrinogen concentrate and cryoprecipitate groups in median length of ICU stay, median length of hospital stay, length of mechanical ventilation, and vasopressor requirement. Clinical complications, including acute myocardial infarction, stroke, acute kidney injury requiring dialysis, septic shock, reoperation, peripheral artery occlusion, deep venous thrombosis, pulmonary embolism, and death up to postoperative day 7 or hospital discharge were similar between groups (Table 5).

No adverse reaction, including fever, headache, rash, dyspnea, vomiting, allergic reaction, anaphylaxis, arterial thrombosis, deep vein thrombosis, thromboembolism, or myocardial infarction were observed in either group.

\section{DISCUSSION}

This prospective and randomized clinical study demonstrates that fibrinogen concentrate administered intraoperatively is as safe and effective as cryoprecipitate in the management of bleeding in pediatric cardiac surgery.

The use of fibrinogen concentrate has been reported to increase plasma fibrinogen levels, and has contributed to the correction of bleeding after cardiovascular surgery. ${ }^{3} \mathrm{~A}$ recent retrospective analysis of adult patients with acute major hemorrhage and acquired hypofibrinogenemia after surgery demonstrated that fibrinogen concentrate increased plasma fibrinogen concentrations more effectively than cryoprecipitate. ${ }^{11}$ Two prospective cohort studies that evaluated aortic valve operation with ascending aorta replacement ${ }^{12}$ and thoracoabdominal aortic aneurysm repair $^{13}$ reported that the intraoperative infusions of fibrinogen concentrate during cardiovascular surgery was associated with reduced bleeding and less need for transfusion requirements. In both studies, patients with diffuse bleeding following $\mathrm{CPB}$ who received thromboelastometry-guided fibrinogen concentrate as a first-line hemostatic therapy exhibited reduced 24-hour drainage volume and requirement for RBC, FFP, and platelet transfusions compared with standard treatment. Similarly, thromboelastography-guided administration of fibrinogen concentrate after CPB reduced postoperative chest-tube drainage volume and FFP transfusion in cyanotic children undergoing cardiac surgery. ${ }^{14}$ Two recent systematic reviews also suggested that fibrinogen concentrate is useful in the treatment of surgical bleeding. ${ }^{15,16}$

Preclinical data demonstrate that the administration of fibrinogen concentrate improves clot quality and reduces bleeding; as fibrinogen levels increase, thromboelastometry and coagulation variables improve and bleeding is more effectively managed. ${ }^{13,17-20}$ The European guidelines for management of bleeding in major trauma recommend fibrinogen administration in cases of significant bleeding accompanied by thromboelastometric signs of a functional fibrinogen deficit or a fibrinogen level $<1.0$ to $2.0 \mathrm{~g} / \mathrm{L} .{ }^{21}$ In a retrospective study of aortic valve operation and ascending aorta replacement, Rahe-Meyer and colleagues ${ }^{18}$ showed that administration 
TABLE 4. Rotational thromboelastometry parameters before and after administration of study medication

\begin{tabular}{|c|c|c|c|c|}
\hline Variable & Time & Fibrinogen (A) & Cryoprecipitate (B) & $\mathbf{A} \times \mathbf{B}$ \\
\hline \multirow{4}{*}{ EXTEM CT, sec } & T0 & $111.5(94-137.3)$ & $123.0(87.5-161.0)$ & 0.510 \\
\hline & $\mathrm{T} 1$ & $100.0(65.5-125.5)$ & $90.0(76.5-111.75)$ & 0.925 \\
\hline & $\mathrm{T} 24$ & $72.0(68.0-81.0)$ & $76.0(65.0-92.5)$ & 0.544 \\
\hline & $\mathrm{T} 48$ & $69.0(61.0-91.0)$ & $82.0(63.5-107.0)$ & 0.155 \\
\hline \multirow[t]{4}{*}{ EXTEM CFT, sec } & T0 & $245.5(206.0-440.0)$ & $299.0(232.3-574.3)$ & 0.180 \\
\hline & $\mathrm{T} 1$ & $200.0(142.5-295.5)$ & $207.5(145.3-282.5)$ & 0.767 \\
\hline & $\mathrm{T} 24$ & $138.0(105.0-199.0)$ & $171.5(142.3-211.8)$ & 0.097 \\
\hline & $\mathrm{T} 48$ & $119.0(108.0-235.0)$ & $163.5(129.3-214.3)$ & 0.052 \\
\hline \multirow[t]{4}{*}{ EXTEM MCF, mm } & T0 & $43.1(40.1-46.1)$ & $42.6(38.9-46.2)$ & 0.952 \\
\hline & $\mathrm{T} 1$ & $50.2(46.0-54.3)$ & $51.7(47.6-55.8)$ & 0.952 \\
\hline & $\mathrm{T} 24$ & $54.4(51.8-57.0)$ & $54.6(52.1-57.1)$ & 0.952 \\
\hline & $\mathrm{T} 48$ & $55.8(51.9-59.8)$ & $54.2(51.5-56.8)$ & 0.952 \\
\hline \multirow[t]{4}{*}{ INTEM CT, sec } & T0 & $226.0(190.0-279.5)$ & $261.0(218.5-424.0)$ & 0.082 \\
\hline & $\mathrm{T} 1$ & $215.0(189.5-235.5)$ & $224.5(208.0-270.8)$ & 0.344 \\
\hline & $\mathrm{T} 24$ & $184.0(162.0-200.0)$ & $184.0(167.8-216.3)$ & 0.397 \\
\hline & $\mathrm{T} 48$ & $195.0(165.0-211.0)$ & $188.5(169.0-232.3)$ & 0.487 \\
\hline \multirow[t]{4}{*}{ INTEM CFT, sec } & T0 & $284.0(193.0-469.0)$ & $291.5(220.3-634.0)$ & 0.345 \\
\hline & $\mathrm{T} 1$ & $180.0(130.3-242.0)$ & $180.0(122.5-263.8)$ & 0.941 \\
\hline & $\mathrm{T} 24$ & $120.0(96.0-172.0)$ & $135.0(109.3-180.3)$ & 0.198 \\
\hline & $\mathrm{T} 48$ & $100.0(87.0-180.0)$ & $132.0(108.5-189.5)$ & 0.123 \\
\hline \multirow[t]{4}{*}{ INTEM MCF, mm } & T0 & $42.1(39.3-44.9)$ & $41.2(37.2-45.2)$ & 0.918 \\
\hline & $\mathrm{T} 1$ & $50.6(45.5-55.7)$ & $49.1(44.6-53.7)$ & 0.918 \\
\hline & $\mathrm{T} 24$ & $53.1(50.6-55.5)$ & $53.3(50.7-55.8)$ & 0.918 \\
\hline & $\mathrm{T} 48$ & $52.5(49.1-55.9)$ & $54.0(51.4-56.7)$ & 0.918 \\
\hline \multirow[t]{4}{*}{ FIBTEM MCF, mm } & T0 & $7.0(5.5-9.0)$ & $6.0(3.8-9.0)$ & 0.189 \\
\hline & $\mathrm{T} 1$ & $11.0(9.0-15.5)$ & $10.0(8.0-12.5)$ & 0.416 \\
\hline & $\mathrm{T} 24$ & $16.0(13.5-18.5)$ & $15.0(9.0-20.0)$ & 0.436 \\
\hline & $\mathrm{T} 48$ & $19.0(15.0-22.0)$ & $17.5(13.0-21.0)$ & 0.336 \\
\hline
\end{tabular}

Values for CT and CFT are presented as median (interquartile range); values for MCF are presented as mean (95\% confidence interval). EXTEM, Extrinsic thromboelastometric clotting assay; $C T$, clotting time; $T 0$, before randomization; $T 1,1 \mathrm{~h}$ after infusion of study drug; $T 24,24$ hours after infusion of study drug; $T 48$, 48 hours after infusion of study drug; $C F T$, clot formation time; $M C F$, maximum clot firmness; INTEM, extrinsic thromboelastometric clotting assay; FIBTEM, fibrin-based thromboelastometric clotting assay. Statistically significant at $P<.05$. *Based on Mann-Whitney $U$ test.

of fibrinogen concentrate guided by FIBTEM assay was associated with reduced transfusion requirements and postoperative bleeding. A recent double-blind trial of

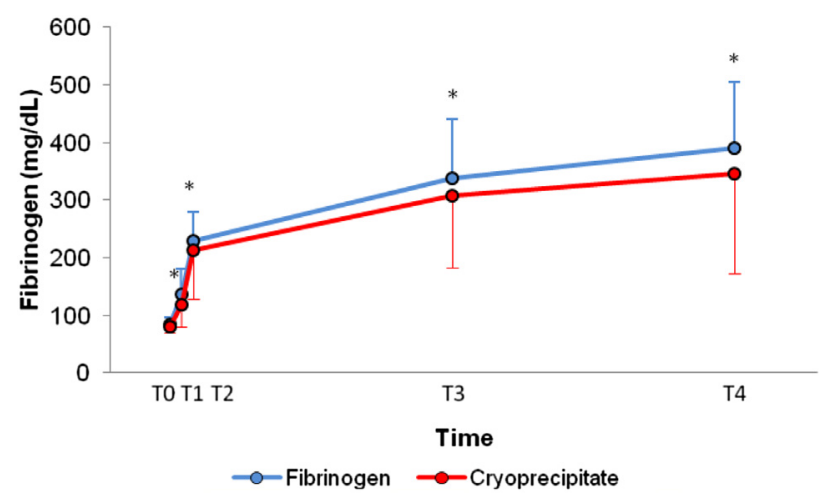

FIGURE 3. Plasma levels of fibrinogen in fibrinogen concentrate and cryoprecipitate groups. There were no differences between groups at the fixed time points. *Plasma levels of fibrinogen are higher at T1, T2, T3, and T4 than T0 in both groups $(P<.001) . T 1$, One hour after study drug infusion; T2, 2 hours after study drug infusion; T3, 24 hours after study drug infusion; $T 4,48$ hours after study drug infusion; $T 0$, before randomization. patients undergoing aortic surgery showed that fibrinogen concentrate significantly reduced transfusion of allogeneic blood products compared with placebo. ${ }^{12}$

Fibrinogen concentrate is a product derived from pooled human plasma from healthy donors. During the manufacturing process, the pasteurization procedure involving virus inactivation and removal steps can reduce but not completely eliminate the risk of infections and immunologic reactions. ${ }^{22}$ The concentration of fibrinogen is standardized, the administration volume is low, and the administration time is short because there is no requirement for thawing. ${ }^{13}$ In addition, fibrinogen concentrate has been shown to be effective and well tolerated in a variety of clinical settings. ${ }^{13}$

Cryoprecipitate is an appropriate comparator for fibrinogen concentrate because it is the only allogeneic blood component that provides high concentrations of fibrinogen. However, cryoprecipitate use has raised safety concerns, including the risk of viral transmission and inflammation. $^{23}$ Other issues include the need for thawing, which can delay administration, and variability in fibrinogen levels. ${ }^{23}$ The efficacy of cryoprecipitate in 
TABLE 5. Clinical outcomes and adverse effects up to postoperative 7 days or hospital discharge

\begin{tabular}{lccc}
\hline \multicolumn{1}{c}{ Variable } & $\begin{array}{c}\text { Fibrinogen } \\
\text { concentrate } \\
(\mathbf{n = 3 0 )}\end{array}$ & $\begin{array}{c}\text { Cryoprecipitate } \\
(\mathbf{n = 3 3 )}\end{array}$ & $\begin{array}{c}\boldsymbol{P} \\
\text { value }\end{array}$ \\
\hline Hospital stay, d & $21(12-32)$ & $20(10-38)$ & .895 \\
Intensive care unit stay, d & $10(6-25)$ & $10(5-24)$ & .930 \\
Length of mechanical & $25(11-119)$ & $43(10-162)$ & .704 \\
$\quad$ ventilation, h & & & \\
Vasopressor requirement & $16(53.3)$ & $23(69.7)$ & .182 \\
Acute kidney injury requiring & $1(3.4)$ & $6(18.2)$ & .109 \\
$\quad$ dialysis & & & \\
Acute myocardial infarction & $2(6.9)$ & $5(15.6)$ & .429 \\
Septic shock & $2(6.9)$ & $5(15.6)$ & .429 \\
Reoperation & $4(13.3)$ & $6(18.2)$ & .735 \\
Stroke/DVT/PE/AO/Death & 0 & 0 & \\
\hline
\end{tabular}

Values for hospital stay, intensive care unit length of stay, and length of mechanical ventilation are presented as median (interquartile range) based on Mann-Whitney $U$ test; values for vasopressor requirement are presented as $\mathrm{n}(\%)$ based on $\chi^{2}$ test; and values for acute kidney injury requiring dialysis, septic shock, and reoperation are presented as n (\%) based on Fisher exact test. DVT, Deep venous thrombosis; $P E$, pulmonary embolism; $A O$, arterial occlusion. Statistically significant at $P<.05$.

improving patient outcomes has not been supported. ${ }^{23,24}$ Despite this, cryoprecipitate is mentioned as an option for fibrinogen supplementation in the latest European trauma management guidelines. ${ }^{21}$

Bennett-Guerrero and colleagues ${ }^{25}$ showed that up to $92 \%$ of patients undergoing cardiac surgery are exposed to blood transfusion. The Transfusion Requirements After Cardiac Surgery Trial study, performed in our center, showed that a restrictive policy of transfusion is safe in adult patients after cardiac surgery. ${ }^{1}$ Reducing allogeneic blood transfusions has been a goal in the perioperative care of complex cardiac surgeries. In a recent study of 152 patients undergoing complex cardiothoracic surgery, ${ }^{26}$ hemostatic therapy based on point-of-care testing reduced exposure to blood products without compromise of clinical end points.

In our study, coagulation tests were immediately available to guide the transfusion protocol. However, clotting factors and thromboelastometry parameters were only evaluated after the end of the study. We observed that, after treatment, clotting factors and fibrinogen levels increased in both groups. However, in the cryoprecipitate group this goal was achieved through an allogeneic blood product, which may be associated with adverse effects in midterm and long-term follow-up. This highlights the potential role of fibrinogen concentrate in decreasing risk in these patients, both due to its effect of increasing fibrinogen levels and reducing exposure to blood transfusion.

Our study has some limitations. We were not able to blind all personnel because it was not feasible to mask the assigned therapy. However, the primary outcome was not a hard end point. This study is also limited by its small sample size and its single-center design. In addition, our patients represented $10 \%$ of all eligible patients during the period of the study. Another point of discussion is that patients of the cryoprecipitate group had a higher proportion of neonates and a longer duration of bypass, which may have influenced the results.

Despite the limitations, our efficacy data are consistent with previous studies in which fibrinogen concentrate improved coagulation measurement and controlled bleeding, thereby reducing transfusion requirements, because it avoided cryoprecipitate as the choice product in the management of bleeding. ${ }^{11-14,18,19,27-29}$ There is a need for more studies with larger number of patients in different surgical conditions to better analyze efficacy and safety of fibrinogen concentrate in bleeding.

\section{CONCLUSIONS}

Our study of children undergoing cardiac surgery shows that fibrinogen concentrate reduces perioperative bleeding without compromising outcomes. Specifically designed studies to ascertain the applicability of the results of our study to adults and different surgical settings are required.

\section{References}

1. Hajjar LA, Vincent JL, Galas FR, Nakamura RE, Silva CM, Santos MH, et al. Transfusion requirements after cardiac surgery: the TRACS randomized controlled trial. JAMA. 2010;304:1559-67.

2. Rahe-Meyer N, Sorensen B. Fibrinogen concentrate for management of bleeding. J Thromb Haemost. 2011;9:1-5.

3. Karlsson M, Ternstrom L, Hyllner M, Baghaei F, Flinck A, Skrtic S, et al. Prophylactic fibrinogen infusion reduces bleeding after coronary artery bypass surgery. A prospective randomised pilot study. Thromb Haemost. 2009;102: 137-44.

4. Stinger HK, Spinella PC, Perkins JG, Grathwohl KW, Salinas J, Martini WZ, et al. The ratio of fibrinogen to red cells transfused affects survival in casualties receiving massive transfusions at an army combat support hospital. J Trauma. 2008;64(Suppl):S79-85; discussion S85;

5. Fenger-Eriksen C, Ingerslev J, Sorensen B. Fibrinogen concentrate-a potential universal hemostatic agent. Expert Opin Biol Ther. 2009;9:1325-33.

6. Groner A. Cryoprecipitate versus commercial fibrinogen concentrate in patients who occasionally require a therapeutic supply of fibrinogen: risk comparison in the case of an emerging transfusion-transmitted infection. Haematologica. 2007; 92:846-9.

7. Solomon C, Pichlmaier U, Schoechl H, Hagl C, Raymondos K, Scheinichen D, et al. Recovery of fibrinogen after administration of fibrinogen concentrate to patients with severe bleeding after cardiopulmonary bypass surgery. $\mathrm{Br} J$ Anaesth. 2010;104:555-62.

8. Stainsby D, MacLennan S, Thomas D, Isaac J, Hamilton PJ. Guidelines on the management of massive blood loss. Br J Haematol. 2006;135:634-41.

9. Karlsson M, Ternstrom L, Hyllner M, Baghaei F, Nilsson S, Jeppsson A. Plasma fibrinogen level, bleeding, and transfusion after on-pump coronary artery bypass grafting surgery: a prospective observational study. Transfusion. 2008;48: 2152-8.

10. Larsen SH, Pedersen J, Jacobsen J, Johnsen SP, Hansen OK, Hjortdal V. The RACHS-1 risk categories reflect mortality and length of stay in a Danish population of children operated for congenital heart disease. Eur J Cardiothorac Surg. 2005;28:877-81.

11. Theodoulou A, Berryman J, Nathwani A, Scully M. Comparison of cryoprecipitate with fibrinogen concentrate for acquired hypofibrinogenaemia. Transfus Apher Sci. 2012;46:159-62.

12. Rahe-Meyer N, Solomon C, Hanke A, Schmidt DS, Knoerzer D, Hochleitner G, et al. Effects of fibrinogen concentrate as first-line therapy during major aortic replacement surgery: a randomized, placebo-controlled trial. Anesthesiology. 2013;118:40-50. 
13. Rahe-Meyer N, Solomon C, Winterhalter M, Piepenbrock S, Tanaka K, Haverich A, et al. Thromboelastometry-guided administration of fibrinogen concentrate for the treatment of excessive intraoperative bleeding in thoracoabdominal aortic aneurysm surgery. J Thorac Cardiovasc Surg. 2009;138:694-702.

14. Cui Y, Hei F, Long C, Feng Z, Zhao J, Yan F, et al. Perioperative monitoring of thromboelastograph on blood protection and recovery for severely cyanotic patients undergoing complex cardiac surgery. Artif Organs. 2010;34:955-60.

15. Kozek-Langenecker S, Sorensen B, Hess JR, Spahn DR. Clinical effectiveness of fresh frozen plasma compared with fibrinogen concentrate: a systematic review. Crit Care. 2011;15:R239.

16. Warmuth M, Mad P, Wild C. Systematic review of the efficacy and safety of fibrinogen concentrate substitution in adults. Acta Anaesthesiol Scand. 2012; 56:539-48.

17. Fries D, Innerhofer $\mathrm{P}$, Perger $\mathrm{P}$, Gutl $\mathrm{M}$, Heil $\mathrm{S}$, Hofmann $\mathrm{N}$, et al. Coagulation management in trauma-related massive bleeding. Recommendations of the Task Force for Coagulation (AGPG) of the Austrian Society of Anesthesiology, Resuscitation and Intensive Care Medicine (OGARI) [in German]. Anasthesiol Intensivmed Notfallmed Schmerzther. 2010;45: 552-61.

18. Rahe-Meyer N, Pichlmaier M, Haverich A, Solomon C, Winterhalter M, Piepenbrock S, et al. Bleeding management with fibrinogen concentrate targeting a high-normal plasma fibrinogen level: a pilot study. Br J Anaesth. 2009;102: 785-92.

19. Fenger-Eriksen C, Jensen TM, Kristensen BS, Jensen KM, Tonnesen E, Ingerslev J, et al. Fibrinogen substitution improves whole blood clot firmness after dilution with hydroxyethyl starch in bleeding patients undergoing radical cystectomy: a randomized, placebo-controlled clinical trial. J Thromb Haemost. 2009;7:795-802.
20. Fenger-Eriksen C, Lindberg-Larsen M, Christensen AQ, Ingerslev J, Sorensen B Fibrinogen concentrate substitution therapy in patients with massive haemorrhage and low plasma fibrinogen concentrations. Br J Anaesth. 2008 101:769-73.

21. Rossaint R, Bouillon B, Cerny V, Coats TJ, Duranteau J, Fernandez-Mondejar E, et al. Management of bleeding following major trauma: an updated European guideline. Crit Care. 2010;14:R52.

22. Levy JH, Welsby I, Goodnough LT. Fibrinogen as a therapeutic target for bleeding: a review of critical levels and replacement therapy. Transfusion 2013 October 9 Epub.

23. Sorensen B, Bevan D. A critical evaluation of cryoprecipitate for replacement of fibrinogen. Br J Haematol. 2010;149:834-43.

24. Stanworth SJ. The evidence-based use of FFP and cryoprecipitate for abnormalities of coagulation tests and clinical coagulopathy. Hematology Am Soc Hematol Educ Program. 2007;179-86.

25. Bennett-Guerrero E, Zhao Y, O'Brien SM, Ferguson TB Jr, Peterson ED Gammie JS, et al. Variation in use of blood transfusion in coronary artery bypass graft surgery. JAMA. 2010;304:1568-75.

26. Weber CF, Gorlinger K, Meininger D, Herrmann E, Bingold T, Moritz A, et al. Point-of-care testing: a prospective, randomized clinical trial of efficacy in coagulopathic cardiac surgery patients. Anesthesiology. 2012;117:531-47.

27. Franchini M, Lippi G. Fibrinogen replacement therapy: a critical review of the literature. Blood Transfus. 2012;10:23-7.

28. Mittermayr M, Streif W, Haas T, Fries D, Velik-Salchner C, Klingler A, et al Hemostatic changes after crystalloid or colloid fluid administration during major orthopedic surgery: the role of fibrinogen administration. Anesth Analg. 2007; 105:905-17.

29. Haas T, Fries D, Velik-Salchner C, Oswald E, Innerhofer P. Fibrinogen in craniosynostosis surgery. Anesth Analg. 2008;106:725-31. 